\title{
Correction to: Methods and indicators for measuring patterns of human exposure to malaria vectors
}

\author{
April Monroe ${ }^{1,2,3^{*}} \mathbb{D}$, Sarah Moore ${ }^{2,3,4}$, Fredros Okumu ${ }^{4,5,6}$, Samson Kiware ${ }^{4}$, Neil F. Lobo ${ }^{7}$, Hannah Koenker ${ }^{1}$, \\ Ellie Sherrard-Smith ${ }^{8}$, John Gimnig ${ }^{9}$ and Gerry F. Killeen ${ }^{4,10,11}$
}

\section{Correction to: Malar J (2020) 19:207}

https://doi.org/10.1186/s12936-020-03271-z

Following publication of the original article [1], the authors reported an error in the formatting of Boxes 1, 3 and 4, affecting either the HTML or the PDF versions of the article.

To explain the errors further:

In the PDF version of the article:

For Box 1, Eq. 7 appeared outside of the box, in the main article body.

While in the HTML version:

For Box 3, the text beginning with "None of the validation steps..." (from the section "Considerations for entomological data collection") appeared erroneously in the box instead of the main article body.

For Box 4, the text beginning with "Direct observation of human behaviour..." (from the section "Considerations for human behavioural data collection") appeared erroneously in the box instead of the main article body.

The original article can be found online at https://doi.org/10.1186/s1293 6-020-03271-z.

*Correspondence: amonro10@jhu.edu

1 Johns Hopkins Center for Communication Programs, PMI VectorWorks Project, Baltimore, MD, USA

Full list of author information is available at the end of the article
The original article [1] has now been updated to correct this.

The publisher apologizes for any inconvenience caused.

\begin{abstract}
Author details
${ }^{1}$ Johns Hopkins Center for Communication Programs, PMI VectorWorks Project, Baltimore, MD, USA. ${ }^{2}$ University of Basel, Basel, Switzerland. ${ }^{3}$ Swiss Tropical and Public Health Institute, Basel, Switzerland. ${ }^{4}$ Environmental Health and Ecological Sciences Department, Ifakara Health Institute, Ifakara, Tanzania. ${ }^{5}$ School of Public Health, Faculty of Health Sciences, University of the Witwatersrand, Parktown, Republic of South Africa. ${ }^{6}$ Institute of Biodiversity, Animal Health and Comparative Medicine, University of Glasgow, Glasgow, UK. ${ }^{7}$ Eck Institute for Global Health, University of Notre Dame, Notre Dame, IN, USA.

${ }^{8}$ MRC Centre for Global Infectious Disease Analysis, Department of Infectious Disease Epidemiology, Imperial College London, Norfolk Place, London W2 1PG, UK. ${ }^{9}$ Division of Parasitic Diseases, Centers for Disease Control and Prevention, Atlanta, GA, USA. ${ }^{10}$ Department of Vector Biology, Liverpool School of Tropical Medicine, Liverpool, UK. ${ }^{11}$ School of Biological, Earth \& Environmental Sciences and Environmental Research Institute, University College Cork, Cork, Republic of Ireland.
\end{abstract}

Published online: 13 July 2020

\section{Reference}

1. Monroe A, Moore S, Okumu F, Kiware S, Lobo NF, Koenker H, SherrardSmith E, Gimnig J, Killeen GF. Methods and indicators for measuring patterns of human exposure to malaria vectors. Malar J. 2020;19:207. https:// doi.org/10.1186/s12936-020-03271-z.

\section{Publisher's Note}

Springer Nature remains neutral with regard to jurisdictional claims in published maps and institutional affiliations.

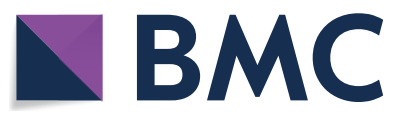

(c) The Author(s) 2020. This article is licensed under a Creative Commons Attribution 4.0 International License, which permits use, sharing, adaptation, distribution and reproduction in any medium or format, as long as you give appropriate credit to the original author(s) and the source, provide a link to the Creative Commons licence, and indicate if changes were made. The images or other third party material in this article are included in the article's Creative Commons licence, unless indicated otherwise in a credit line to the material. If material is not included in the article's Creative Commons licence and your intended use is not permitted by statutory regulation or exceeds the permitted use, you will need to obtain permission directly from the copyright holder. To view a copy of this licence, visit http://creativeco mmons.org/licenses/by/4.0/. The Creative Commons Public Domain Dedication waiver (http://creativecommons.org/publicdomain/ zero/1.0/) applies to the data made available in this article, unless otherwise stated in a credit line to the data. 